\title{
Thermal Mitigation of Stormwater Management Pond Outflows Using Geothermal Cooling
}

\author{
Erik Janssen and Tim Van Seters
}

Sustainable Technologies Evaluation Program (STEP) of the Toronto and Region Conservation Authority (TRCA), Vaughan, Ontario.

\begin{abstract}
During warm weather, urban surfaces heat up in the sun. Runoff from these surfaces during rain events is much warmer than under natural conditions. Warming is increased in stormwater management ponds due to solar heating. Without intervention, stormwater management pond outflows often exceed temperature thresholds set for the protection of aquatic ecosystems. Several strategies and technologies exist to mitigate outflow temperatures. Using monitoring data from a recent pilot project, we present geothermal cooling as a new thermal mitigation option. The pilot was implemented in a stormwater management pond located in Brampton, Ontario in 2019. The geothermal cooling system used a surface water heat exchanger to absorb excess heat energy from the warm stormwater outflows and, via a circulating hydronic fluid in a closed circuit, it rejected that heat energy to the deep ground using a vertical borehole. A system model was developed that was in good agreement with the monitoring data. The model was used to estimate the size of a full scale system for the pond. This pilot demonstrates several key benefits of geothermal cooling. It has good performance, and it is also cost-effective, scalable, retrofittable, space efficient and highly engineerable, and it has minimal visual impact on the pond.
\end{abstract}

\section{Introduction}

The health of streams and rivers is dependent on a variety of factors including hydrology, temperature, geomorphology, habitat structure, and water quality (Karr 1991). Among these, water temperature is a critical element as it regulates both biotic and abiotic processes in streams (Nelson and Palmer 2007). Therefore it can be both a driving and constraining factor for the health and survival of aquatic organisms.

Urbanized landscapes provide less shade for a watercourse and supply thermally enriched storm water runoff from heated paved surfaces (Hester and Bauman 2013; Van Buren et al. 2000a). When runoff is drained through stormwater management (SWM) ponds, solar heating of open pond water causes further warming of the stormwater (Van Buren et al. 2000b), often to levels beyond the tolerance thresholds of downstream aquatic life (Chu et al. 2009). Early work by Galli (1990) in Maryland indicated maximum temperature increases from late April to mid-September of $4.2^{\circ} \mathrm{C}$ to $6.1{ }^{\circ} \mathrm{C}$ in four extended detention dry and wet basins, with the wet pond showing the highest outflow temperatures. Sabouri et al. (2016) monitored the temperature of four ponds in Guelph and Kitchener, Ontario over a 3 y period. Differences in inlet and outlet summer event mean temperatures in three of the ponds averaged $3.2{ }^{\circ} \mathrm{C}, 5.4{ }^{\circ} \mathrm{C}$ and $7.2^{\circ} \mathrm{C}$. Only one pond showed $<1{ }^{\circ} \mathrm{C}$ change in temperature, which was attributed to the bottom draw outlet and groundwater seepage into the pond.
A variety of best management practices have been devised to mitigate the thermal impacts of SWM ponds on aquatic life. These include outlets that draw water from below the permanent pool water level or discharge only during the cooler nighttime period, and stone filled cooling trenches installed downstream of the pond outlet (OMOE 2003).

Monitoring programs in Ontario have shown these practices to provide thermal mitigation benefits to varying degrees of success (Van Seters et al. 2019). In some cases, application at the site level is constrained by physical factors and operational considerations. For instance, cooling trenches require significant land availability between pond outlet and stream to provide adequate detention storage for outflow cooling (Roa-Espinosa et al. 2003). Subsurface draw outlets take advantage of the tendency for ponds to stratify thermally (McEnroe et al. 2013; Song et al. 2013; Marsalek et al. 2003) and are therefore more effective in deep ponds ( $>3 \mathrm{~m}$ ) that can accommodate lower outlet elevations. However, sediment cleanout from deep ponds can be more expensive than from shallow ponds and bottom draw outlets are more susceptible to clogging with age as sediment accumulates. The release of dissolved phosphorus and metals through redox reactions caused by anoxic conditions near the pond bottom (Mayer et al. 1999) has also led researchers to question whether bottom draw outlets may reduce the water quality benefit of ponds by facilitating release of these contaminants to receiving waters (Song et al. 2013).

Janssen, Erik, and Tim Van Seters. 2022. "Thermal Mitigation of Stormwater Management Pond Outflows Using Geothermal Cooling."

Journal of Water Management Modeling 30: C483. https://doi.org/10.14796/JWMM.C483

(c) Janssen and Van Seters 2022. www.chijournal.org ISSN 2292-6062. 
Some cooling technologies, which are commonplace in other disciplines, have not yet been considered for thermal mitigation applications. For example, geothermal heating and cooling systems are increasingly being incorporated into high performance buildings. Geothermal systems utilize the relatively stable year-round temperatures of the deep ground (on the scale of $10^{\circ} \mathrm{C}$ ) as a source of heat energy in the winter and a source of cooling in summer. Monitoring studies have demonstrated high levels of performance (Janssen et al. 2015) and in Ontario, geothermal drilling is an established sector with clear regulations for safety (Ontario Regulation 98/12) and standards of practice (ANSI/CSA C448).

The capacity of geothermal technologies to mitigate the adverse thermal impacts of ponds on streams has not yet been explored. This article provides monitoring and modeling results from a small scale pilot geothermal cooling system installed in a SWM pond in Brampton, Ontario. The overarching aim of the pilot was to understand system performance such that a full scale system could be modeled and sized.

\section{Methodology}

\subsection{Study site}

The SWM pond used in this study is located at 60 Upperlinks Drive in Brampton, Ontario. It treats runoff from a medium density residential catchment. It has a surface area of $\sim 3000 \mathrm{~m}^{2}$ and a permanent pool depth of $\sim 2 \mathrm{~m}$. During a storm event, the pond level rises as stormwater runoff from the subdivision enters the pond from the pond inlet. Once the water level exceeds the permanent pool depth, it drains through the top draw Hickenbottom outlet, typically over the course of $2 \mathrm{~d}$. It enters a vault (interior dimensions: $2.3 \mathrm{~m} \times 1.8 \mathrm{~m} \times 1.8 ; \mathrm{L} \times \mathrm{W} \times \mathrm{H}$ ) through a pipe, and then it discharges via another pipe to an outlet channel. The outlet channel drains to a nearby stream. A bird's eye view of the pond (from Google Earth) is shown in Figure 1.

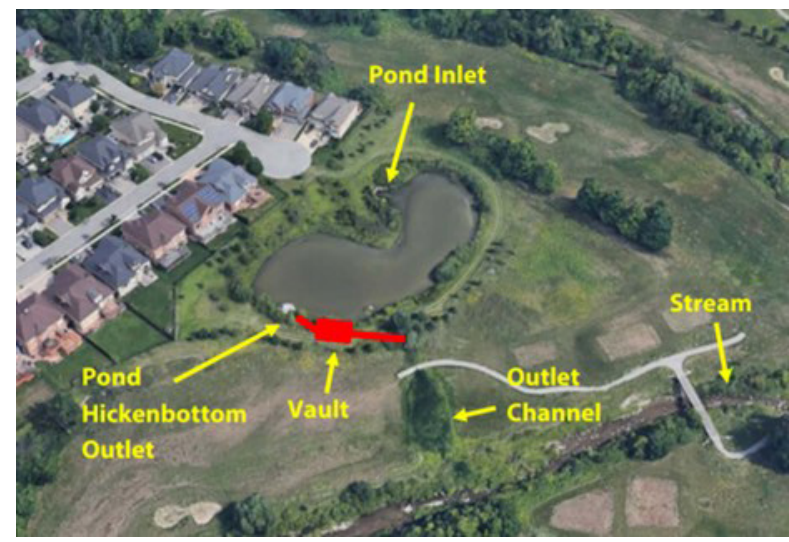

Figure 1 The pilot geothermal based thermal mitigation system was installed at an SWM pond in Brampton, Ontario.

\subsection{Geothermal system overview}

An illustration of the system is shown in Figure 2. Note that it is not to scale, nor is the geographical positioning of components correct. The system was a closed hydronic circuit where piping connected a surface water heat exchanger (SHX) to a ground heat exchanger (GHX). A pump continuously circulated a hydronic fluid around the circuit. The SHX was placed in the path of the pond outflows such that they must pass through it. The hydronic fluid circulating through the SHX was cooler than the warm stormwater outflows. This temperature difference forced heat energy from the stormwater into the hydronic fluid, cooling the stormwater in the process. In the GHX, the hydronic fluid was warmer than the deep ground. This temperature difference forced heat energy from the hydronic fluid into the deep ground, cooling the fluid to its original temperature. This cycle was used to continuously cool the stormwater. Note that the hydronic circuit was not open to the environment. The hydronic fluid exchanged heat with the deep ground and the stormwater though the heat exchanger walls, but the fluid did not leave the closed circuit.

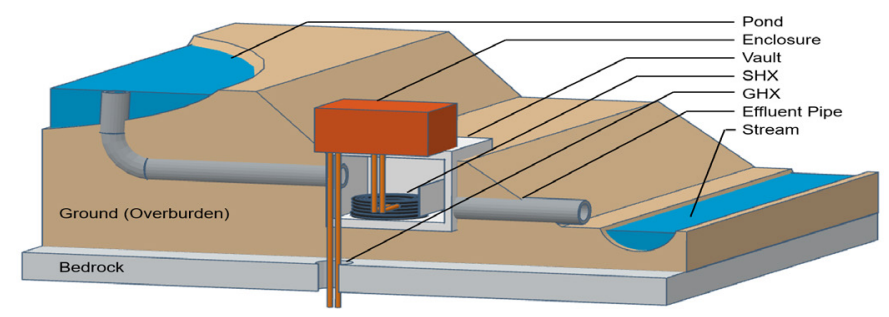

Figure 2 3D cross section of the geothermal cooling system.

\subsection{Geothermal system components}

\section{Ground heat exchanger}

The GHX consisted of a single vertical borehole installed by a local driller with Environmental Compliance Approval (ECA) from the Ontario Ministry of Environment and in adherence with ANSI/ CSA C448. The borehole was $13 \mathrm{~cm}$ in diameter and extended $183 \mathrm{~m}$ into the ground. There was $6 \mathrm{~m}$ of overburden (i.e. soil and dirt) before reaching the sedimentary bedrock. A single factory sealed U-bend of $1.25 \mathrm{in} .(3.2 \mathrm{~cm})$ nominal diameter DR11 high density polyethylene (HDPE) pipe was inserted into the borehole which was backfilled with a thermally enhanced bentonite grout mixture with a thermal conductivity of $2.1 \mathrm{~W} /\left(\mathrm{m}^{\circ} \mathrm{C}\right)$.

During cooling operation, the hydronic fluid entered one side of the U-bend and then travelled to the bottom before coming up on the other side, rejecting its heat to the deep ground in the process. A single borehole was selected due to budgetary constraints. It was not intended to meet the full cooling load of the pond. Rather, it was used to measure and model system performance such that a full scale system could be sized. 


\section{Surface water heat exchanger}

There are different ways to implement the SHX. In this pilot, it consisted of $230 \mathrm{~m}$ of $0.75 \mathrm{in}$. (19 mm) nominal diameter DR11 HDPE pipe that was placed in the existing vault as a large bundle (Figure 3). There were four concentric rows and twelve vertical layers of pipe in the bundle. This size HDPE pipe was also used as spacer material for both the concentric rows and the vertical layers. To install the SHX in the vault, it was split into four sections, each having three vertical layers of pipe. This allowed enough clearance for the sections to fit through the overflow opening of the vault. The four sections were then connected in parallel to the rest of the system. The parallel connections were necessary to reduce the pressure drop across the SHX and to achieve the desired hydronic flow rate through the closed loop hydronic circuit.

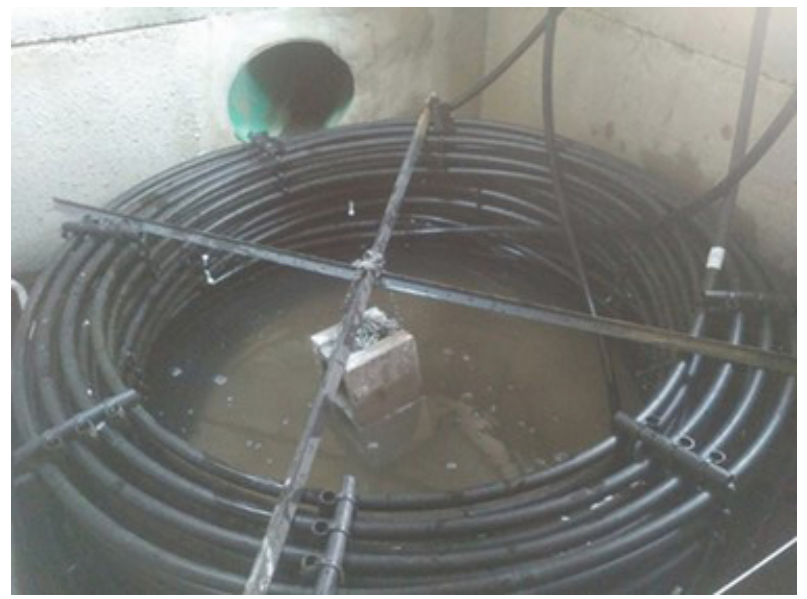

Figure 3 The SHX was installed in the existing vault at the SWM pond.

Figure 3 shows the vault interior when it was drained for the installation of the SHX. Above the SHX is the $0.38 \mathrm{~m}$ diameter vault inlet pipe. During normal operation, the SHX was submerged in water and this was achieved using a baffle wall placed after the SHX and a weir partially covering the $0.76 \mathrm{~m}$ diameter discharge pipe. Water was forced to flow under the baffle wall and over the weir before exiting the vault and this ensured good interaction between the stormwater and the SHX.

\section{Mechanical enclosure}

A mechanical enclosure housed the circulator pump, pipe connections, monitoring equipment, and other hydronic system components (valves, manifold, gauges). The enclosure was a $0.6 \mathrm{~m} \times 0.6 \mathrm{~m} \times 1.5 \mathrm{~m}$ metal job box (Figure 4) typically used for outdoor storage of tools at construction sites. The hydronics package was assembled offsite inside the enclosure and then installed onsite as a modular package. It was placed on top of the vault which facilitated connections to the $\mathrm{SHX}, \mathrm{GHX}$, and other components.

\section{Power}

The geothermal cooling system used a circulator pump. In this pilot, the pump consumed $\sim 50 \mathrm{~W}$ of power and was left on continuously throughout the monitoring period. A full scale permanent system would require a connection to the electrical grid due to maintenance considerations. However, since this was a temporary small scale retrofit, the low power requirements of the pump worked well with an offgrid system composed of a 1 kW photovoltaic (PV) array and battery storage.
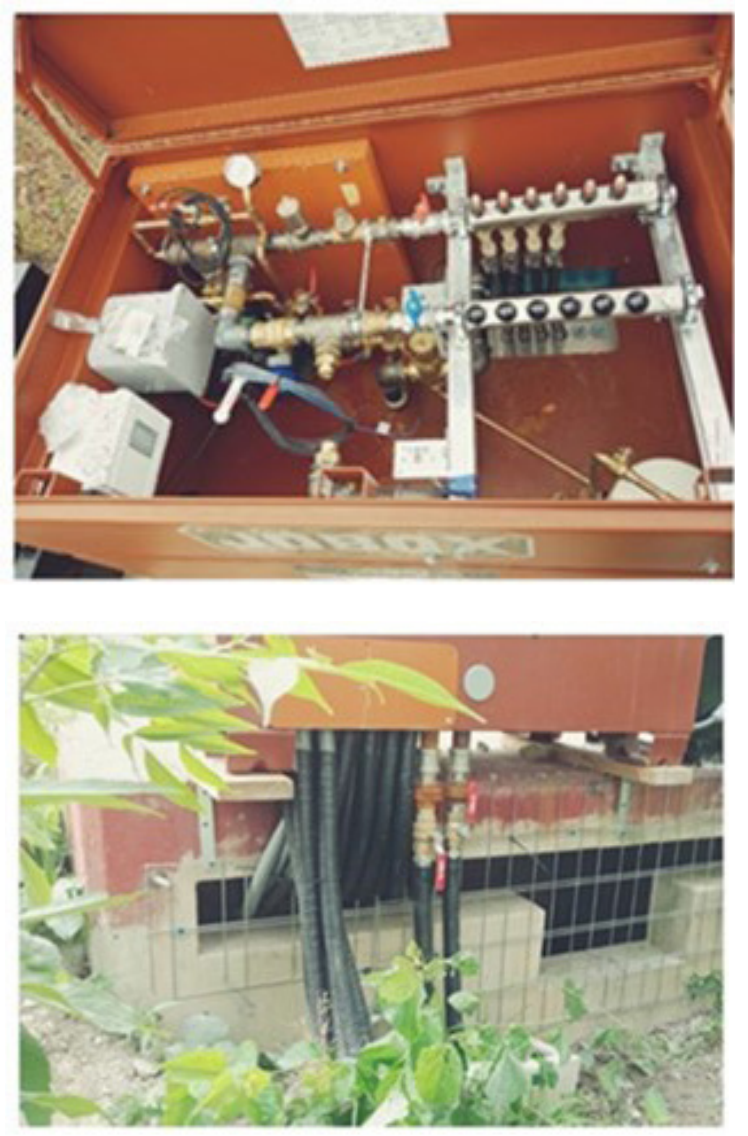

Figure 4 A metal job box was used to house the circulator pump, pipe connections, monitoring equipment, and other components (upper); it was placed on top of the existing vault at the SWM pond (lower).

Battery storage was placed in a metal job box situated on the vault adjacent to the mechanical enclosure for the hydronic components. The offgrid system received a special inspection from the Electrical Safety Authority (ESA) to ensure compliance with all codes and regulations. It provided power without interruption throughout the monitoring period.

\subsection{Geothermal system model}

Figure 5 shows a simplified schematic of the system for modeling purposes. Parameters shown in the schematic are described in Equations 1 to 4. 


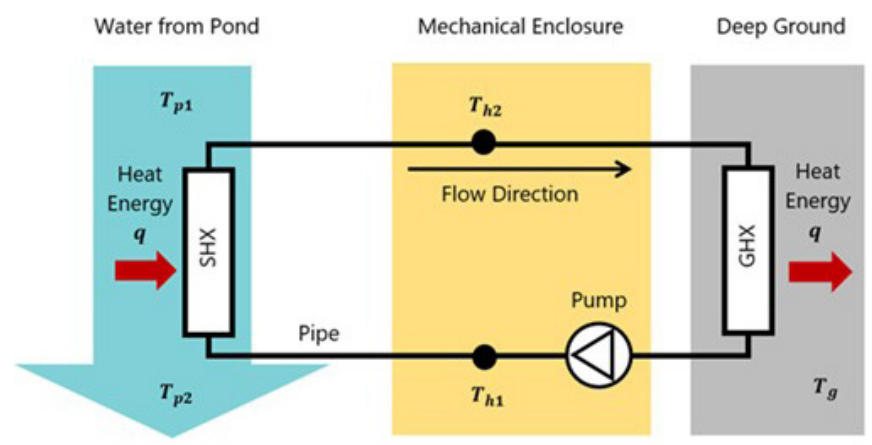

Figure 5 Schematic of the geothermal system used for modeling.

The heat transfer required to cool a given stormwater flow rate by a given amount is shown in Equation 1:

$$
q_{r}=F_{p} \cdot \rho_{p} \cdot C_{p} \cdot\left(T_{p 1}-T_{p 2}\right)
$$

where:

$$
\begin{aligned}
q_{r}= & \text { required cooling capacity }(\mathrm{W}), \\
F_{p}= & \text { flow rate of the stormwater from the pond }\left(\mathrm{m}^{3} / \mathrm{s}\right), \\
\rho_{p}= & \text { density of water }\left(\mathrm{kg} / \mathrm{m}^{3}\right), \\
C_{p}= & \text { specific heat capacity of water }\left(\mathrm{J} /\left(\mathrm{kg}^{\circ} \mathrm{C}\right)\right), \\
T_{p 1}= & \text { stormwater temperature in vault upstream of the } \\
& \mathrm{SHX}\left({ }^{\circ} \mathrm{C}\right), \text { and } \\
T_{p 2}= & \text { stormwater temperature in vault downstream of } \\
& \text { the } \mathrm{SHX}\left({ }^{\circ} \mathrm{C}\right) .
\end{aligned}
$$

The heat transfer to an SHX composed of HDPE pipe is described by Equation 2 (Kavanaugh and Rafferty 2014, p. 141):

$$
q_{S H X}=\left(\frac{L_{S H X}}{R_{S H X}}\right) \cdot L M T D_{S H X}
$$

where:

$$
\begin{aligned}
L_{S H X}= & \text { length of the SHX immersed in the pond outflow } \\
& (\mathrm{m}), \\
R_{S H X}= & \text { thermal resistance of the } \mathrm{SHX}\left(\mathrm{m}^{\circ} \mathrm{C} / \mathrm{W}\right) \text {, and } \\
L M T D_{S H X}= & \text { log-mean temperature difference across the } \mathrm{SHX} \\
& \left({ }^{\circ} \mathrm{C}\right) .
\end{aligned}
$$

Log-mean temperature difference was used to account for the fact that the temperature difference across the heat exchanger wall is not a constant value for each point along the length of the heat exchanger. The parameter $L M T D_{S H X}$ is further defined in Equation 3:

$\operatorname{LMTD}_{S H X}=\left[\frac{T_{p 1}+T_{p 2}}{2}-T_{h 2}-\left(\frac{T_{p 1}+T_{p 2}}{2}-T_{h 1}\right)\right] \cdot\left[\ln \left(\frac{\frac{T_{p 1}+T_{p 2}}{2}-T_{h 2}}{\frac{T_{p 1}+T_{p 2}}{2}-T_{h 1}}\right)\right]^{-1}$

where:
$T_{h 1}=$ hydronic fluid temperature leaving the $\mathrm{GHX}\left({ }^{\circ} \mathrm{C}\right)$, and

$T_{h 2}=$ hydronic fluid temperature entering the $\mathrm{GHX}$ $\left({ }^{\circ} \mathrm{C}\right)$.

Overall, Equation 2 shows that heat transfer is linearly proportional to a term representing the temperature difference between the stormwater and the hydronic fluid $L M T D_{S H X^{\prime}}$ with the constant of proportionality given by the ratio of $L_{S H X}$ to $R_{S H X}$. Heat transfer to the deep ground is described by Equation 4 (Kavanaugh and Rafferty 2014, p. 53):

$$
q_{G H X}=\left(\frac{L_{G H X}}{R_{G H X}}\right) \cdot\left(\frac{T_{h 1}+T_{h 2}}{2}-T_{g}\right)
$$

where:

$$
\begin{aligned}
q_{G H X}= & \text { heat transfer to the deep ground }(\mathrm{W}), \\
L_{G H X}= & \text { borehole length (borehole depth multiplied by } \\
& \text { quantity; } \mathrm{m}), \\
R_{G H X}= & \text { thermal resistance of } \mathrm{GHX}\left(\mathrm{m}^{\circ} \mathrm{C} / \mathrm{W}\right) \text {, and } \\
T_{g}= & \text { average deep ground temperature in the vicinity } \\
& \text { of the } \mathrm{GHX}\left({ }^{\circ} \mathrm{C}\right) .
\end{aligned}
$$

Just as in Equation 2, Equation 4 shows that heat transfer to the ground is linearly proportional to the temperature difference between the hydronic fluid and the deep ground, with the constant of proportionality given by the ratio of $L_{G H X}$ to $R_{G H X}$. In a steady state, the hydronic fluid has no net heat gain. The heat transferred from the pond outflow to the SHX equals the heat transferred from the GHX to the deep ground. This is shown in Equation 5:

$$
q=q_{r}=q_{S H X}=q_{G H X}
$$

where:

$$
\begin{aligned}
& q=\text { steady state heat transfer from pond outflow to } \\
& \text { deep ground }(\mathrm{W}) \text {. }
\end{aligned}
$$

The relationship between $T_{h 1}$ and $T_{h 2}$ is defined by the heat transfer and the hydronic flow rate of the system according to Equation 6 (note that $T_{h 1}$ cannot be below $T_{g}$ ):

$T_{h 1}=\left(T_{h 2}-\frac{q}{\rho_{h} \cdot F_{h} \cdot C_{h}}\right)$ if $\left(T_{h 2}-\frac{q}{\rho_{h} \cdot F_{h} \cdot C_{h}}\right)>T_{g}$ else no solution

where:

$$
\begin{aligned}
& F_{h}=\text { flow rate of the hydronic fluid through the closed } \\
& \quad \text { circuit }\left(\mathrm{m}^{3} / \mathrm{s}\right), \\
& \rho_{h}=\text { density of the hydronic fluid }\left(\mathrm{kg} / \mathrm{m}^{3}\right) \text {, and } \\
& C_{h}=\text { specific heat capacity of the hydronic fluid }(\mathrm{J} /(\mathrm{kg} \\
& \left.\left.{ }^{\circ} \mathrm{C}\right)\right) .
\end{aligned}
$$

The hydronic fluid may be water, an ethanol solution, a propylene glycol solution, or some other heat transfer solution. Ethanol and propylene glycol are commonly used in geothermal systems and are considered non-toxic. This pilot simply used water during summer 2019. Substituting Equation 6 into Equation 4 yields Equation 7, which can be used to solve for a value of $T_{h 2}$ : 


$$
T_{h 2}=q \cdot\left(\frac{R_{G H X}}{L_{G H X}}\right)+\frac{q}{2 \cdot \rho_{h} \cdot F_{h} \cdot C_{h}}+T_{g}
$$

Note that $q$ is a function of $T_{p 1}$ and $T_{p 2}$ (Equation 1 and Equation 5) and therefore so is $T_{h 2}$. It is then possible to find the value of $T_{h 1}$ using Equation 6. Putting these equations together yields Equation 8 which describes the system:

$$
0=\left(\frac{L_{S H X}}{R_{S H X}}\right) \cdot L M T D_{S H X}-\left(\frac{L_{G H X}}{R_{G H X}}\right) \cdot\left(\frac{T_{h 1}+T_{h 2}}{2}-T_{g}\right)
$$

Equation 8 can be more simply expressed as Equation 9 (ignoring the physical constants for density and specific heat capacity):

$$
0=f\left(T_{p 1}, T_{p 2}, F_{p}, F_{h}, R_{G H X}, R_{S H X}, L_{G H X}, L_{S H X}, T_{g}\right)
$$

It is possible to solve Equation 9 for any given parameter provided all the other parameters are known. A numerical solution is sometimes needed (a solver for $T_{p 2}$ coded in Python has been provided in a public online repository at https://github. com/janssenerikw/Geothermal_SWM_Pond_Thermal_Mitigation). Note that Equation 9 is a steady state heat transfer model that neglects heat transfer between adjacent boreholes. This is permissible when the boreholes are spaced sufficiently distant so that interactions between adjacent boreholes are negligible. An example of this would be a geothermal cooling system using boreholes placed several meters apart. A more complex model is needed to accurately capture heat transfer in more tightly packed arrangements, and this would require the use of a more detailed approach for system sizing and design, likely involving a commercially available software package for GHX modeling. However, regardless of borehole spacing, Equation 9 is simple to use, and this makes it expedient for applications like feasibility and prefeasibility studies, if not detailed system design.

\subsection{Preliminary system sizing}

Equation 9 can be used to size components of the geothermal system for the pilot SWM pond. The parameters for the outflow temperature and flow rate $\left(T_{p 1}\right.$ and $\left.F_{p}\right)$ must be known, as must a desired set point temperature $\left(T_{p 2}\right)$.

The thermal resistances of the $\mathrm{SHX}$ and $\mathrm{GHX}\left(R_{G H X}\right.$ and $\left.R_{S H X}\right)$ are constants that will vary with the site and materials used. $R_{G H X}$ can be measured directly using a thermal conductivity (TC) test but could also be estimated using data from TC tests that have already been conducted in the local area (available from local geothermal drillers). The ground temperature $\left(T_{g}\right)$ will vary over the course of the summer, but it could be estimated as well for the purposes of system sizing and design.

Equation 9 would then be used to find values for the system hydronic flow rates $\left(F_{h}\right)$ and heat exchanger sizes $\left(L_{G H X}\right.$ and $L_{S H X}$ ) to meet the cooling load. In this pilot project, the value of $L_{G H X}$ was constrained at $183 \mathrm{~m}$ due to the project budget and the value of $L_{S H X}$ was constrained at approximately $230 \mathrm{~m}$ by the volume available in the vault and the minimum bend radius of the 0.75 in. (19 mm) DR1 1 HDPE pipe. Power for the circulator pump was also constrained since it was being supplied by an offgrid system.

With these constraints in mind, Equation 9 was used to determine a design hydronic flow rate. This is shown in Figure 6. The parameters used to create this plot are shown in Table 1. It was assumed that stormwater must be cooled from $30^{\circ} \mathrm{C}$ to $24^{\circ} \mathrm{C}$; water was used as the fluid in the hydronic circuit; the thermal resistance of the SHX and GHX were standard values from other installations (discussed in sections 2.9 and 2.11); and the ground temperature was $10^{\circ} \mathrm{C}$.

Figure 6 plots the required SHX length and hydronic flow rates to cool different stormwater outflows. If SHX length is constrained to approximately $230 \mathrm{~m}$, then the system can potentially cool outflows between $0.3 \mathrm{~L} / \mathrm{s}$ and $0.4 \mathrm{~L} / \mathrm{s}$. Note that this is lower than the normal range of outflows from SWM ponds because it is a small scale pilot system that is not intended to meet the full thermal load. It is also worth noting that the warm temperatures occur primarily during lower flows, rather than during peak flows.

A hydronic flow rate between $15 \mathrm{~L} / \mathrm{min}$ and $20 \mathrm{~L} / \mathrm{min}$ was then the target for the system design. Beyond this range, benefits are rapidly diminishing. A hydronic flow rate of $17 \mathrm{~L} / \mathrm{min}$ was achieved in practice, using a low cost energy efficient circulator pump powered by the offgrid system.

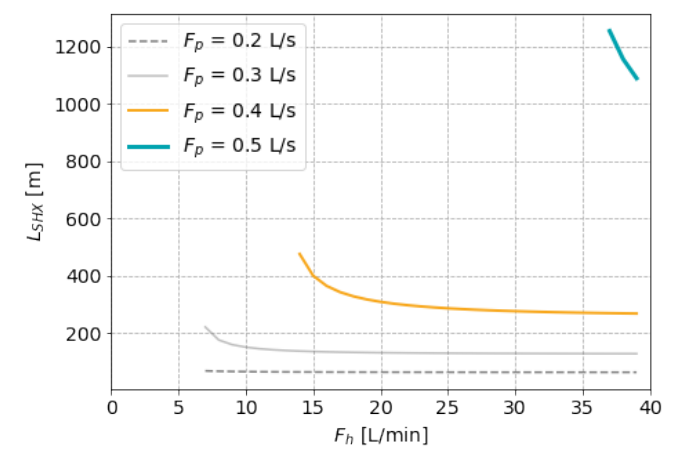

Figure 6 Different values of $F_{h}, L_{S H X}$, and $F_{p}$ were considered when sizing the system; points along each curve are solutions to Equation 9.

Table 1 Parameter values used for preliminary system sizing.

\begin{tabular}{ccc}
\hline Parameter & Unit & Value \\
\hline$\rho_{p}$ & $\mathrm{~kg} / \mathrm{m}^{3}$ & 1000 \\
$C_{p}$ & $\mathrm{~J} /\left(\mathrm{kg}^{\circ} \mathrm{C}\right)$ & 4184 \\
$T_{p 1}$ & ${ }^{\circ} \mathrm{C}$ & 30 \\
$T_{p 2}$ & ${ }^{\circ} \mathrm{C}$ & 24 \\
$R_{S H X}$ & $\left(\mathrm{~m}^{\circ} \mathrm{C}\right) / \mathrm{W}$ & 0.14 \\
$\rho_{h}$ & $\mathrm{~kg} / \mathrm{m}^{3}$ & 1000 \\
$C_{h}$ & $\mathrm{~J} /\left(\mathrm{kg}^{\circ} \mathrm{C}\right)$ & 4184 \\
$L_{G H X}$ & $\mathrm{~m}$ & 183 \\
$R_{G H X}$ & $\left(\mathrm{~m}^{\circ} \mathrm{C}\right) / \mathrm{W}$ & 0.21 \\
$T_{g}$ & ${ }^{\circ} \mathrm{C}$ & 10 \\
\hline
\end{tabular}




\subsection{Monitoring}

Table 2 shows the key monitoring points and hardware used during the pilot project. Averaged data were collected at $5 \mathrm{~min}$ intervals.

Table 2 Monitoring points and hardware used during pilot.

\begin{tabular}{|c|c|c|c|c|}
\hline$\#$ & Parameter & Symbol & Description & $\begin{array}{l}\text { Accuracy } \\
\text { of Sensor }\end{array}$ \\
\hline 1 & $\begin{array}{l}\text { Hydronic fluid supply } \\
\text { temperature (from GHX) }\end{array}$ & $\mathrm{T}_{\mathrm{h} 1}$ & $\begin{array}{l}\text { HOBO S-TMB-M002 Temperature Smart Sensor } \\
\text { connected to Hobo U30 Logger; mounted in } \\
\text { thermal well using thermal grease. }\end{array}$ & $\pm 0.2^{\circ} \mathrm{C}$ \\
\hline 2 & $\begin{array}{l}\text { Hydronic fluid return } \\
\text { temperature (to GHX) }\end{array}$ & $\mathrm{T}_{\mathrm{h} 2}$ & $\begin{array}{l}\text { HOBO S-TMB-M002 Temperature Smart Sensor } \\
\text { connected to Hobo U30 Logger; mounted in } \\
\text { thermal well using thermal grease. }\end{array}$ & $\pm 0.2^{\circ} \mathrm{C}$ \\
\hline 3 & $\begin{array}{l}\text { Hydronic fluid volumetric } \\
\text { flow rate }\end{array}$ & $F_{h}$ & $\begin{array}{l}\text { Grunfoss Vortex Flowsensor Standard (VFS } \\
5-100 \mathrm{~L} / \mathrm{min} \text { ) connected to Hobo U30 Logger }\end{array}$ & $\begin{array}{l} \pm 1.5 \% \\
\mathrm{~L} / \mathrm{min}\end{array}$ \\
\hline 4 & $\begin{array}{l}\text { Stormwater temperature } \\
\text { at vault inlet }\end{array}$ & $T_{p 1}$ & $\begin{array}{l}\text { HOBO S-TMB-M002 Temperature Smart Sensor } \\
\text { connected to Hobo U30 Logger }\end{array}$ & $\pm 0.2^{\circ} \mathrm{C}$ \\
\hline 5 & $\begin{array}{l}\text { Stormwater temperature } \\
\text { at vault outlet }\end{array}$ & $T_{p 2}$ & $\begin{array}{l}\text { HOBO S-TMB-M002 Temperature Smart Sensor } \\
\text { connected to Hobo U30 Logger }\end{array}$ & $\pm 0.2^{\circ} \mathrm{C}$ \\
\hline 6 & $\begin{array}{l}\text { Stormwater volumetric } \\
\text { flow rate through vault }\end{array}$ & $F_{p}$ & $\begin{array}{l}\text { Solinst Levelogger Edge Model } 3001 \text { in vault } \\
\text { with } 22.5^{\circ} \text { V-notch weir }\end{array}$ & $\pm 3 \mathrm{~mm}$ \\
\hline 7 & Rainfall & $\mathrm{N} / \mathrm{A}$ & $\begin{array}{l}\text { Collected from a local Toronto and Region } \\
\text { Conservation Authority weather station } \\
\text { (within } 1.5 \mathrm{~km} \text { ) }\end{array}$ & \\
\hline
\end{tabular}

\subsection{Cooling capacity equations}

The cooling capacity of the system was determined from the monitoring data in two different ways based on the change in temperature of the pond outflows and corresponding stormwater flow rate (Equation 10), and on the change in temperature across the SHX and GHX and the hydronic flow rate (Equation 11):

$$
\begin{aligned}
& q_{p}=\rho_{p} \cdot F_{p} \cdot C_{p} \cdot\left(T_{p 1}-T_{p 2}\right) \\
& q_{h}=\rho_{h} \cdot F_{h} \cdot C_{h} \cdot\left(T_{h 2}-T_{h 1}\right)
\end{aligned}
$$

In Equation 10, $F_{p}$ was determined using a $22.5^{\circ} \mathrm{V}$-notch weir that partially covered the outlet from the vault to the discharge pipe. The readings from the corresponding level sensor were transformed into a volumetric flow rate using the equation for a $22.5^{\circ} \mathrm{V}$-notch weir (units: L/s), taking into account the height of the bottom of the $\mathrm{V}$-notch from the vault floor. This is shown in Equation 12:

$$
F_{p}=274.4 \cdot(x-(0.475))^{2.5}
$$

where:

$$
x=\text { reading from the level sensor }(\mathrm{m}) \text {. }
$$

Having two different options to measure cooling capacity was helpful but ultimately temperature and flow rate measurements in a closed pipe are more accurate than those in an open channel. The water is fully mixed in the closed pipe hydronic system so there is no error resulting from a cross sectional temperature distribution.
Furthermore, the concrete walls of the vault itself introduced some level of cooling that would be captured in the stormwater measurements but not in the hydronic system measurements. It follows that this pilot relied more heavily on the hydronic measurements (Equation 11) to determine the geothermal system cooling capacity, and the change in stormwater temperature measurements across the SHX were used more as a verification of the results.

\subsection{Verification of key sensors}

The accuracies of key sensors were verified prior to deployment at the SWM pond site. Verification took place at the Archetype Sustainable House (ASH) Lab at the Kortright Centre for Conservation in Vaughan, Ontario. For the temperature sensors, verification proceeded by placing all sensors simultaneously in a wet well calibrator and then recording the measurements from the sensor for different calibrator temperature setpoints. Sensors connected to the same datalogger and the same channels were used throughout the monitoring period. Results are shown in Table 3. The temperatures for the hydronic system and the pond outflows were matched to within $\pm 0.2^{\circ} \mathrm{C}$.

Readings from the hydronic system flow sensor $\left(F_{h}\right)$ were also verified prior to deployment. This was done once the flow sensor was installed along with all other components in the mechanical enclosure. The mechanical enclosure was configured such that flowing water would leave the system and enter an open bucket. By temporarily diverting the water supplied by the pump to another bucket of known volume, and for a known amount of time, the average flow rate from the pump was determined and compared against the readings from the sensor. Results are shown in Table 4. At most, there was a 3\% deviation from the stated manufacturer calibration equation.

Table 3 Temperature sensor verification results prior to deployment.

\begin{tabular}{lccc}
\hline & \multicolumn{3}{c}{ Calibrator Set-Point } \\
\hline Sensor & $10^{\circ} \mathrm{C}$ & $20^{\circ} \mathrm{C}$ & $30^{\circ} \mathrm{C}$ \\
$T_{p 1}$ & 10.2 & 20.0 & 29.7 \\
$T_{p 2}$ & 10.3 & 20.0 & 29.9 \\
$T_{h 1}$ & 10.3 & 19.9 & 29.8 \\
$T_{h 2}$ & 10.4 & 19.9 & 29.8 \\
\hline
\end{tabular}

Table 4 Hydronic flow rate sensor verification results prior to deployment.

\begin{tabular}{ccccccc}
\hline $\begin{array}{c}\text { Pump } \\
\text { Speed }\end{array}$ & $\begin{array}{c}\text { Sensor } \\
\text { Voltage [V] }\end{array}$ & $\begin{array}{c}\text { Sensor Flow } \\
{[\mathrm{L} / \mathrm{min}]}\end{array}$ & $\begin{array}{c}\text { Fill Time } \\
{[\mathrm{s}]}\end{array}$ & $\begin{array}{c}\text { Fill Volume } \\
{[\mathrm{L}]}\end{array}$ & $\begin{array}{c}\text { Actual Flow } \\
{[\mathrm{L} / \mathrm{min}]}\end{array}$ & $\begin{array}{c}\text { Difference } \\
{[\%]}\end{array}$ \\
\hline 4 & 1.29 & 30.7 & 29.1 & 14.5 & 29.9 & -2.1 \\
3 & 1.07 & 23.8 & 36.9 & 14.7 & 23.8 & 1.3 \\
2 & 0.87 & 17.4 & 51.7 & 14.7 & 17.0 & -1.5 \\
1 & 0.79 & 14.8 & 62.5 & 15.0 & 14.4 & -3.0 \\
\hline
\end{tabular}




\subsection{Ground temperature and $R_{G H X}$ estimates}

The average deep ground temperature must be known to validate the system model shown in Equation 9, but it is not something that can be directly measured on a continuous basis. In this pilot, it was estimated by rearranging Equation 4 and expressing the ground temperature in terms of other parameters that are known constants or are directly measurable. This is shown in Equation 13. Substituting Equation 11 into Equation 13 yields Equation 14:

$$
\begin{aligned}
& T_{g}=\left(\frac{T_{h 1}+T_{h 2}}{2}\right)-q_{G H X} \cdot\left(\frac{R_{G H X}}{L_{G H X}}\right) \\
& T_{g}=\left(\frac{T_{h 1}+T_{h 2}}{2}\right)-\rho_{h} \cdot F_{h} \cdot C_{h} \cdot\left(T_{h 2}-T_{h 1}\right) \cdot\left(\frac{R_{G H X}}{L_{G H X}}\right)
\end{aligned}
$$

$L_{G H X}$ was a known constant and hydronic system temperatures were continuously monitored. However, while $R_{G H X}$ could be estimated, it was not initially known. $R_{G H X}$ is a constant for a given borehole and constant steady state flow conditions. If it is determined at one point in time, then it is known at all points in time provided nothing about the borehole or circulating hydronic fluid changes.

$R_{G H X}$ is the sum of component thermal resistances in the thermal circuit between the hydronic fluid and the deep ground. The component thermal resistances include the surface thermal resistance between the hydronic fluid and interior of the pipe, the HDPE pipe material, the grout, the ground, and interactions with ground water or other boreholes. It can be estimated from first principles (Kavanaugh and Rafferty 2014, pp. 52-73) but it can also be determined empirically. In this pilot, it was determined empirically. Equation 4 and Equation 11 were used to define Equation 15, which was then used to fit the monitoring data and solve for $R_{G H X}$ :

$$
q=\rho_{h} \cdot F_{h} \cdot C_{h} \cdot\left(T_{h 2}-T_{h 1}\right)=\left(\frac{L_{G H X}}{R_{G H X}}\right) \cdot\left(\frac{T_{h 1}+T_{h 2}}{2}-T_{g}\right)
$$

To apply Equation $15, T_{g}$ needs to be known, but the initial goal of this exercise was to estimate $T_{g}$ and, unlike $R_{G H X^{\prime}} T_{g}$ is not a constant. It will change throughout the summer as heat is rejected to the ground, but it can be measured at specific points in time. In this pilot, $T_{g}$ was determined for a specific point in time by turning the system off and letting the hydronic fluid equilibrate with the ground over a full $5 \mathrm{~d}$ period.

The system was then turned on and the average temperature of the hydronic fluid in the borehole was determined using the data collected for $F_{h}$ and $T_{h 1}$. The $T_{h 1}$ sensor provided the temperature data and the $F_{h}$ sensor was used to determine when the hydronic fluid that had been sitting in the borehole had made a complete pass across the $T_{h 1}$ sensor.

After this was done, the system resumed normal operation. With the ground temperature known, $8 \mathrm{~h}$ of steady state data for
$T_{h 1}$ and $T_{h 2}$ from the following day was used to determine $R_{G H X}$ according to Equation 15. Data from TC tests conducted by located drillers suggested that $R_{G H X}$ might range from $0.10 \mathrm{~m}{ }^{\circ} \mathrm{C} / \mathrm{W}$ to 0.22 $\mathrm{m}{ }^{\circ} \mathrm{C} / \mathrm{W}$. The ground temperature was also estimated at different points during the monitoring period using a similar approach.

In summary, the ground temperature was determined for one point in time by temporarily disabling the system and letting the hydronic fluid equilibrate with the ground. The known ground temperature was then used to provide an estimate of $R_{G H X}$ Since $R_{G H X}$ is a constant, it was then used to provide a continuous estimate of $T_{g}$ throughout the monitoring period based on the measured amount of heat being rejected to the ground.

\subsection{Ground temperature model}

To confirm that the ground temperature results were reasonable, the data were fitted to a simple heat transfer model:

$$
T_{i}=T_{i-1}+\alpha \cdot q_{i-1}-\beta \cdot\left(T_{i-1}-T_{0}\right)
$$

where:

$$
\begin{aligned}
& T_{i}= \text { ground temperature for } 5 \text { min time interval } i\left({ }^{\circ} \mathrm{C}\right), \\
& T_{i-1}= \text { ground temperature for the time interval } \\
& \text { immediately preceding interval } i\left({ }^{\circ} \mathrm{C}\right), \\
& a= \text { empirically determined constant of } \\
& \text { proportionality, }
\end{aligned}
$$

The model assumed that the ground temperature for the 5 min time step $i$ during the monitoring period $\left(T_{i}\right)$ was equal to the estimated initial ground temperature from the previous interval $\left(T_{i-1}\right)$ plus an additional term that was proportional to the heat energy rejected to the ground during the previous interval $\left(q_{i-1}\right)$ and then subtracted by a final term that was proportional to heat dissipation to the far ground (with the far ground temperature represented by $T_{0}$ ). In the model, $a$ and $\beta$ are empirically determined constants of proportionality related to the heat transfer. The far ground temperature was estimated to be equal to the starting ground temperature (which was measured using an approach similar to that described in section 2.9).

\section{$2.11 R_{S H X}$ estimates}

$R_{\text {SHX }}$ was estimated using an approach similar to that used to estimate $R_{G H X}$. Equation 11 was substituted into Equation 2 to yield Equation 17 and monitoring data was fitted to find the solution for $R_{S H X}$ :

$$
q=\rho_{h} \cdot F_{h} \cdot C_{h} \cdot\left(T_{h 2}-T_{h 1}\right)=\left(\frac{L_{S H X}}{R_{S H X}}\right) \cdot L M T D_{S H X}
$$


RSHX is impacted by changes in the hydronic flowrate and, during August, the system was intentionally operated with a lower hydronic flowrate. RSHX was therefore calculated both for high and low flowrates. The thermal resistance of the SHX is the sum of component thermal resistance between the hydronic fluid inside the SHX and the stormwater flowing over it.

Previous work has evaluated thermal resistance of 0.75 in. (19 mm) DR11 HDPE in still water and it was found that approximately half (58\%) of the thermal resistance was due to the wall of the plastic pipe. (Hansen 2011) This component of thermal of resistance is straightforward to calculate and can then be used to estimate an upper limit for $R_{S H X}$. The thermal resistance of the pipe wall is given in Equation 18 (Kavanaugh and Rafferty 2014, p. 143):

$$
R_{p}=\ln \left(\frac{d_{o}}{d_{i}}\right) \cdot\left(2 \pi k_{p}\right)^{-1}
$$

where:

$$
\begin{aligned}
& R_{p}=\text { thermal resistance of pipe wall }\left(\mathrm{m}^{\circ} \mathrm{C} / \mathrm{W}\right), \\
& d_{0}=\text { outside pipe diameter }(\mathrm{mm}), \\
& d_{i}=\text { inside pipe diameter }(\mathrm{mm}), \text { and } \\
& k_{p}=\text { thermal conductivity of pipe wall material }(\mathrm{W} /(\mathrm{m} \\
& \left.\left.{ }^{\circ} \mathrm{C}\right)\right) .
\end{aligned}
$$

For $0.75 \mathrm{in}$. (19 mm) DR11 HDPE pipe, $d_{i}=21.6 \mathrm{~mm}, d_{o}$ $=26.4 \mathrm{~mm}$ and $k_{p}$ is $0.45 \mathrm{~W} / \mathrm{m}^{\circ} \mathrm{C}$, yielding an estimate of approximately $0.14 \mathrm{~m}^{\circ} \mathrm{C} / \mathrm{W}$ for $R_{S H X}$ in an open reservoir.

\subsection{Overview of monitoring period}

The system was operated continuously for summer 2019 starting in May and extending past September, occasionally being disabled for ground temperature measurements. Monitoring data were used to calculate the cooling capacity of the system and validate the system model. The model was used to estimate the size of a full scale system for the pond.

\section{Results}

\subsection{Cooling capacity}

Figure 7 shows the temperatures upstream and downstream of the geothermal cooling system throughout the monitoring period and Figure 8 shows the data for a 2 week period in July. Peak flows from the pond correspond to storm events. Outflow temperatures from the pond nearly reached $30^{\circ} \mathrm{C}$. Note that this was not a failure of the geothermal cooling system because it was a small scale pilot that was not designed to meet the full cooling load of the pond.

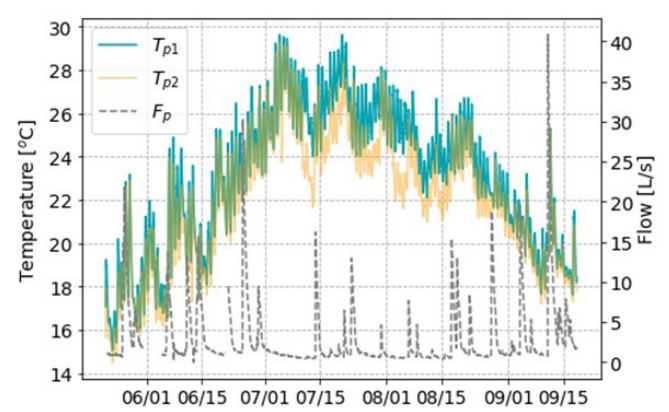

Figure 7 Upstream and downstream temperatures, as well as the stormwater flow rate, for the monitoring period.

Figure 8 shows that, during high flows, the upstream and downstream temperatures converge. This is because the volume of water is too great for the system to have a noticeable impact on the outflow temperatures. However, during periods of low flow, up to $4{ }^{\circ} \mathrm{C}$ of cooling was observed.

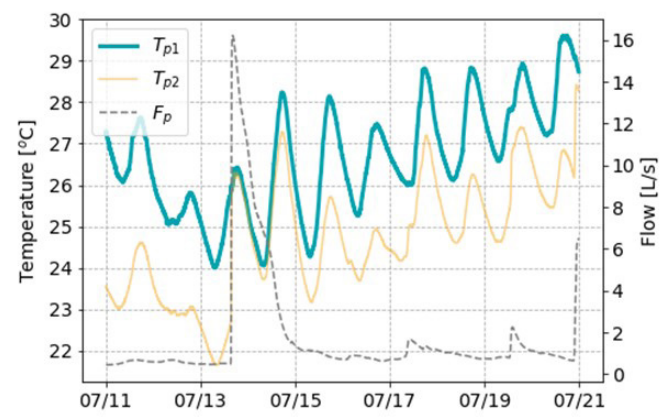

Figure 8 The cooling benefit of the geothermal system is more clearly shown at a shorter time scale.

Figure 9 plots the cooling capacity of the system with respect to the pond outflow temperature. For much of August, the system was intentionally operated at a lower pump speed to gather additional data for model verification. $F_{h}$ was reduced down from $17.4 \mathrm{~L} / \mathrm{min}$ to $7.3 \mathrm{~L} / \mathrm{min}$, causing a decrease in cooling capacity (shown in grey). Figure 9 also aggregates the data according to the estimated ground temperature and greater cooling capacity is seen when the ground temperature was cooler (in blue).

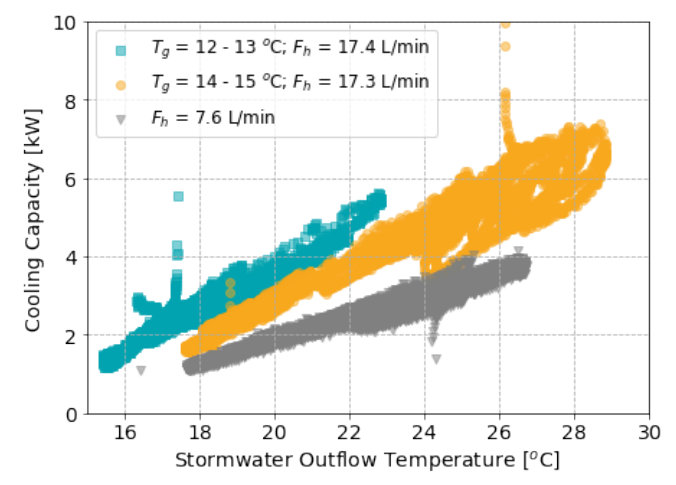

Figure 9 The greatest cooling capacity occurred when ground temperatures were cooler and the hydronic flow rate was near the design value. 
Figure 10 and 11 plot the time-series data from Figure 7 as frequency histograms. Figure 12 provides a box-and-whisker plot of the temperature data.

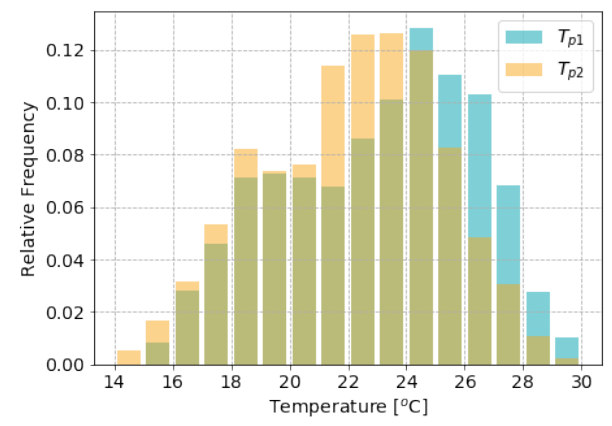

Figure 10 Cooling is evident from the shift between the distributions of the upstream and downstream temperatures.

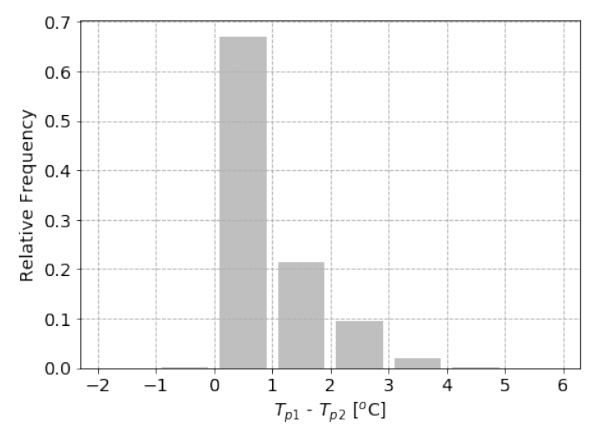

Figure 11 The geothermal system provided up to $4^{\circ} \mathrm{C}$ of cooling.

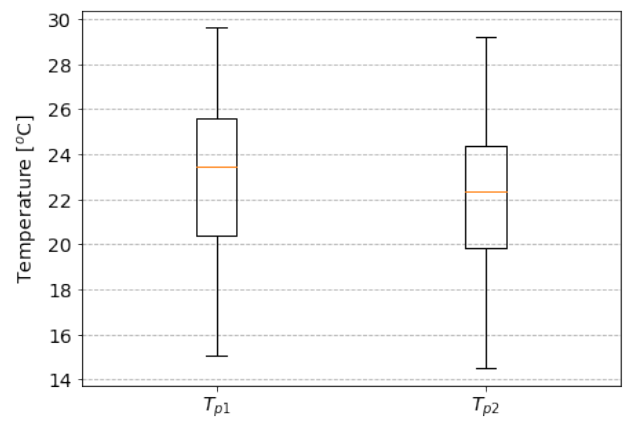

Figure 12 Cooling is also clear from the downward shift of the box-and-whisker plot for the downstream outflow temperatures.

\subsection{Ground temperature model}

The deep ground temperature was estimated using Equation 14 and then fit to the model in Equation 16. This is shown in Figure 13. Fit parameters for $\alpha, \beta$ and $T_{0}$ were $1.8 \times 10^{-7}, 1.7 \times 10^{-4}$, and $11.8^{\circ} \mathrm{C}$, respectively. The coefficient of determination $\left(R^{2}\right)$ for the calculated ground temperature versus the modeled ground temperature was 0.86 , which indicates that the model is very good at explaining the observed ground temperature trend.

The deep ground temperature increased because the rate of heat rejection to the ground was greater than could be dissipated. It was estimated to have reached $16^{\circ} \mathrm{C}$ during the monitoring. This is important for system sizing. The greatest cooling capacity is required from the system in late July but this is when the ground is at its warmest, reducing system cooling capacity.

Data are missing from July when the system was left off to measure the ground temperature. During this period, it was clear that the ground began to cool rapidly once there was no longer any heat rejection. Data are missing from August when the system was intentionally operated at a lower hydronic flow rate. The change in flow rate led to a stepwise jump in ground temperature on the scale of $1^{\circ} \mathrm{C}$ to $2^{\circ} \mathrm{C}$, which is believed to be an artifact of the analysis rather than a physical change. It was a consequence of the assumption of a constant value of $R_{G H X}$. When the hydronic flow rate was reduced, the GHX thermal resistance that had previously been calculated was no longer accurate. Note that the modeled value of ground temperature was then used to verify the geothermal system model in section 3.5 .

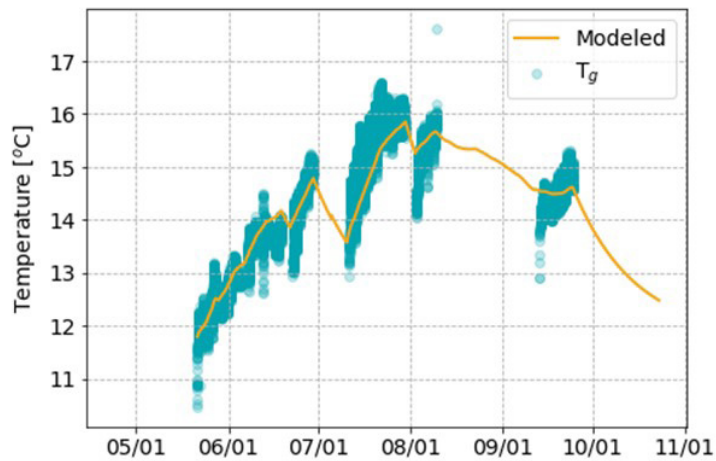

Figure 13 The calculated ground temperature agrees well with the model.

\subsection{GHX thermal resistance}

The ground temperature was measured as $13.6^{\circ} \mathrm{C}$ on July 10 by temporarily disabling the system for $5 \mathrm{~d}$ and allowing the system to equilibrate with the ground temperature. On July 11 , $8 \mathrm{~h}$ of steady state data were used to estimate $R_{G H X}$ by fitting the data to Equation 15. The fit is shown in Figure 14. $R_{G H X}$ was estimated at $0.21 \mathrm{~m}^{\circ} \mathrm{C} / \mathrm{W}$. This was within the expected range based on the data shared by a local driller $\left(0.10 \mathrm{~m}{ }^{\circ} \mathrm{C} / \mathrm{W}\right.$ to 0.22 $\left.\mathrm{m}^{\circ} \mathrm{C} / \mathrm{W}\right)$. 


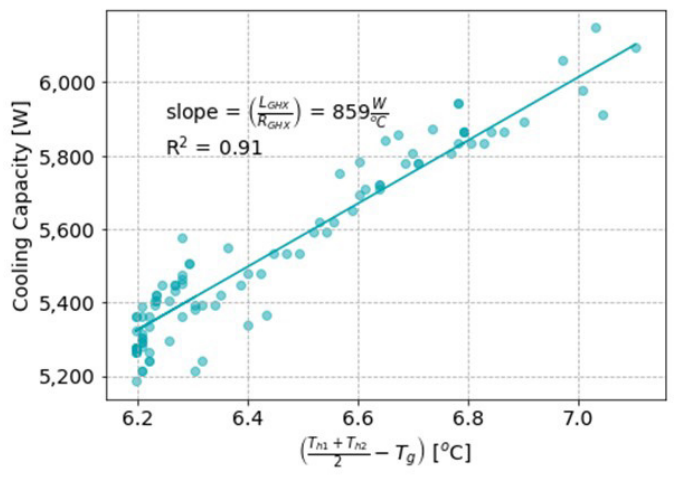

Figure 14 Monitoring data was used to estimate the thermal resistance of the GHX.

\subsection{SHX thermal resistance}

$R_{S H X}$ was determined by plotting the monitoring data and fitting to Equation 17. This is shown in Figure 15. Note that data were aggregated according to the hydronic flow rate (shown as different colors) prior to fitting. Previous research found that the thermal resistance of the $\mathrm{SHX}$ in an open reservoir was $\sim 0.14 \mathrm{~m}{ }^{\circ} \mathrm{C} / \mathrm{W}$. This pilot found it to be $0.17 \mathrm{~m}{ }^{\circ} \mathrm{C} / \mathrm{W}$ for higher hydronic flow rates (17.4 L/min) and $0.20 \mathrm{~m}{ }^{\circ} \mathrm{C} / \mathrm{W}$ for lower hydronic flow rates $(7.3 \mathrm{~L} /$ $\mathrm{min})$. The discrepancy is likely related to the physical differences between an open reservoir and an enclosed vault.

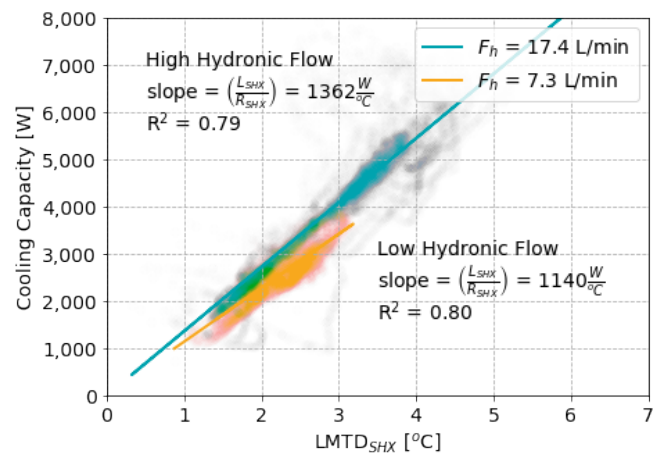

Figure 15 The monitoring data were aggregated according to the hydronic flow rate and then used to estimate $R_{S H X}$.

\subsection{Model verification}

When the ground temperature model, the GHX thermal resistance, and the SHX thermal resistance had been defined, it was possible to apply the system model (Equation 9) to the monitoring data. The model was used to predict $T_{p 2}$ based on the measured or estimated values of $T_{p 1^{\prime}} F_{p^{\prime}} F_{h^{\prime}} R_{G H X^{\prime}} R_{S H X^{\prime}} L_{G H X^{\prime}} L_{S H X}$ and $T_{g^{\prime}}$ and then to compare it with the measured value of $\mathrm{T}_{p 2}$. This required a numerical solution since Equation 9 is an implicit equation with respect to $T_{p 2}$.

Figure 16 shows the measured values for $T_{p 1}, T_{p 2}$ and $F_{p}$ as well as the model predicted value of $T_{p 2}$. For clarity, the model is shown for a shorter time period, over the course of several days in July, when the hydronic flow rate averaged $17.4 \mathrm{~L} / \mathrm{min}$. The model predicted that $T_{p 2}$ was slightly higher than the actual monitoring data. This is because the model considered only the geothermal system and neglected passive cooling from the walls and floor of the vault which themselves are in contact with the cool ground.

Figure 17 shows stormwater temperatures upstream and downstream of the geothermal system and the stormwater flow rate when the geothermal system was turned off (with no flow through the hydronic circuit) for a ground temperature measurement. The temperatures converge under higher flows but a difference of up to $0.5^{\circ} \mathrm{C}$ was observed for lower flows and higher stormwater temperatures. This demonstrates that the vault is introducing a small amount of cooling capacity and explains the discrepancy between measured and predicted temperatures in Figure 16. Note there is outlying data for a brief period on July 5; the reason was not identified.

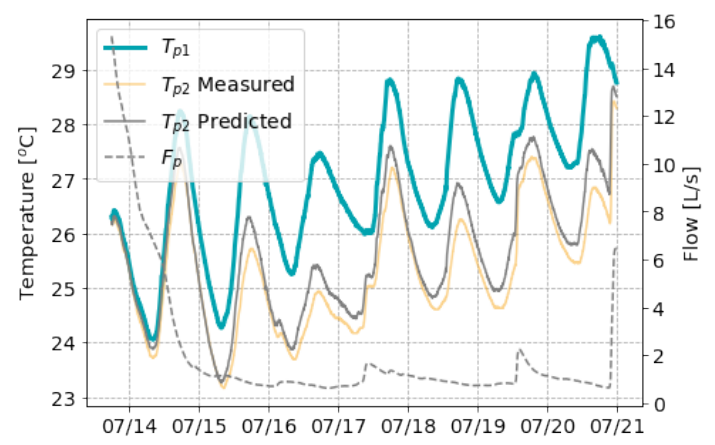

Figure 16 The modeled values of the pond outflow temperatures downstream of the geothermal cooling system were slightly higher than the measured temperatures because the model did not account for passive cooling from the walls and floor of the vault.

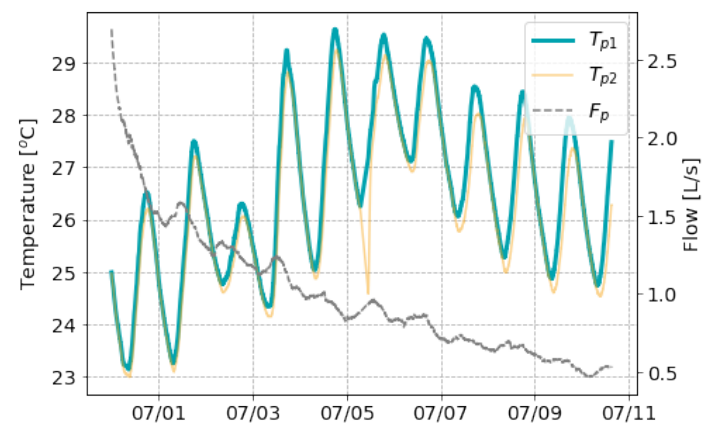

Figure 17 When the geothermal system was turned off, a small amount of cooling was observable from the vault itself. This is clear for higher stormwater temperatures and lower stormwater flow rates, where a temperature reduction up to $0.5^{\circ} \mathrm{C}$ was observed. 


\subsection{Full system sizing}

As a final exercise, the calibrated geothermal system model and ground temperature model were used to generate an estimate for a full scale geothermal system at the pilot pond. Stormwater temperature and flow rate data from June 1 to September 15 were considered. A number of modeling iterations were then performed on these data. Iterations considered different GHX sizings by incrementally increasing the number of deep (183 m) boreholes. The SHX was assumed to be composed of HDPE pipe. The ratio of SHX to GHX was held constant (i.e. there was $230 \mathrm{~m}$ of SHX for every $183 \mathrm{~m}$ of GHX). Hydronic flowrate increased at 17.4 L/min per borehole.

As output, each modeling iteration considered the fraction of time (with respect to the total duration of time from June 1 to September 15) that the stormwater temperature downstream of the $\mathrm{SHX}$ was below a setpoint of $24^{\circ} \mathrm{C}$. The modeling iterations also assumed that the system turned on only when the outflow temperature exceeded $24^{\circ} \mathrm{C}$ since this was simple to implement and would help maintain cooler ground temperatures. Results are shown in Figure 18 and Figure 19.

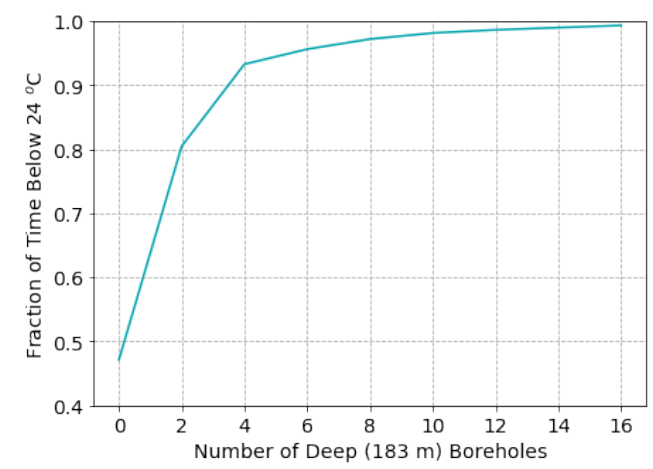

Figure 18 A geothermal cooling system consisting of 6 deep vertical boreholes would maintain outflow temperatures $<24{ }^{\circ} \mathrm{C}$ for $96 \%$ of the time.

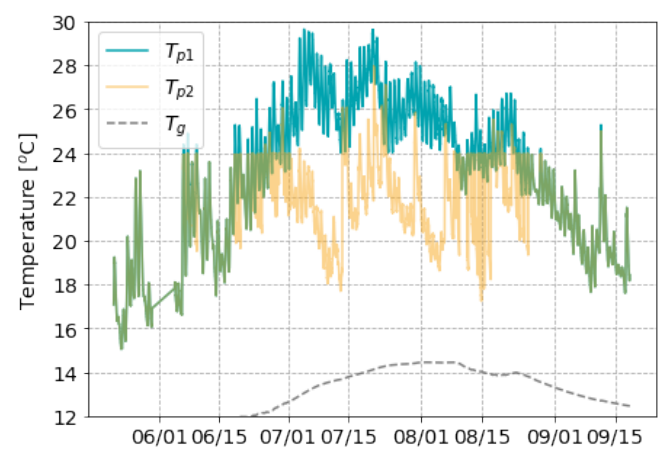

Figure 19 The modeled downstream temperature from a geothermal cooling system with 6 deep boreholes shows that the $24^{\circ} \mathrm{C}$ target temperature would only be exceeded during brief periods (for the 2019 data).
With no geothermal system, the pond outflows are below $24{ }^{\circ} \mathrm{C}$ for approximately $50 \%$ of the time from June 1 to September 15, 2019. A geothermal system with 6 boreholes would be enough to maintain the outflow below $24{ }^{\circ} \mathrm{C}$ for $96 \%$ of the time. There are rapidly diminishing returns beyond 6 boreholes. This is because the remaining $5 \%$ of the time consists of short duration thermal peaks. This is illustrated in Figure 20, where the thermal load $\left(q_{r}\right)$ is the cooling capacity required to cool the pond outflows to $24^{\circ} \mathrm{C}$. The thermal load peaks coincide with storm events. During an interevent period, a warm layer of water develops at the top of the pond. That warm water then rapidly drains during a storm event as a large amount of water enters through the inlet. This results in brief high temperature high flow rate periods from the pond that would be a challenge for any thermal mitigation system to manage.

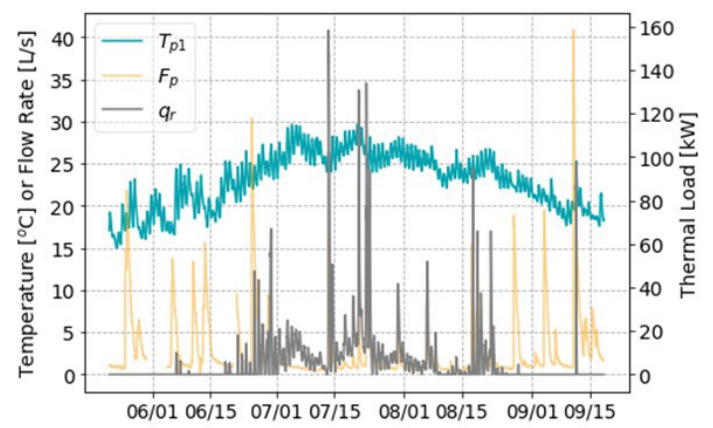

Figure 20 This pond has short duration thermal load peaks.

\section{Discussion}

\subsection{Benefits and drawbacks of geothermal cooling}

\section{Performance}

This pilot showed that a relatively small system composed of 6 deep boreholes would keep outflow temperatures below $24{ }^{\circ} \mathrm{C}$ for $96 \%$ of the time during summer 2019. Other measures, like cooling trenches, have shown to vary greatly in their performance (Van Seters et al. 2019; Sabouri et al. 2013).

Cost

The cost of the GHX installation at this location was \$17 000 (CAD) for the single borehole. The cost for several boreholes is estimated to be lower, between $\$ 10000$ and $\$ 15000$ per borehole. It is also estimated that most of the cost of a full scale geothermal cooling installation is for the boreholes. It follows that the full scale system cost for this pilot pond is estimated to be $<\$ 200000$. Compared to other measures, particularly those that require moving large amounts of earth (like cooling trenches), the geothermal cooling approach is cost competitive.

\section{Space efficiency}

The system generates cooling by using the deep ground and a large amount of area at the surface is not strictly required, 
although it would be beneficial to limit interactions between adjacent boreholes. This may lend itself to specific application where space for a thermal mitigation system is constrained.

\section{Visual impact}

SWM ponds are often used as natural areas for local residents and some thermal mitigation measures impact the natural setting of the pond. The only above ground component of the geothermal cooling system is the mechanical enclosure. It is small and not impactful on the pond appearance.

\section{Engineerability}

This pilot showed that the cooling from the system is well described by a relatively simple set of equations, making it a highly engineerable solution, both for new SWM ponds and for retrofits.

\section{Retrofitting and scalability}

The geothermal cooling approach is highly scalable. It is possible to create a system with a single borehole or one with dozens, or more. It is also possible to retrofit geothermal cooling into existing ponds or as an addition to existing thermal mitigation systems that are underperforming, such as cooling trenches.

\section{Drawbacks}

The main drawback of geothermal cooling is that it requires an active mechanical component, the circulator pump. While it is not the only thermal mitigation approach to utilize active components (controlled nighttime release would be another example) the active nature of the system introduces a potential point of failure.

It should first be noted that at the most basic level the system is not very complex. It is just a large loop of piping with a circulating fluid. Circulator pumps are both robust and inexpensive. The pump ought to last a considerable time (years) before requiring servicing or replacement. Furthermore, for the pilot system, the pump itself was inexpensive $(\sim 250)$ so a replacement pump is not a significant expense.

The system can be easily winterized using a nontoxic propylene glycol or ethanol solution and it needs only to be turned off for the summer and then back on again for the winter with no other elaborate procedures required. Furthermore, with simple low cost off-the-shelf components, it is possible to monitor key system parameters remotely using automated emails to service contractors should any monitored parameters move outside the range of expected readings.

\subsection{Heat transfer improvements}

Contact time can be a helpful way to qualitatively understand the heat transfer occurring in this system. It could be taken to mean the transit time of water across the SHX and could be expected to indirectly indicate the quality of interaction between the stormwater and SHX. Contact time is proportional to the inverse of flow rate for any fixed spatial and geometrical arrangement of vault and SHX. As could be expected, low flows result in longer contact times. Greater reductions in stormwater temperature are also seen for low flows because there is a lower volume of water to cool with the fixed capacity offered by the geothermal system.

The vault and bundle of coil used in this pilot were expedient options given physical space constraints, but they likely do not represent the ideal spatial and geometrical arrangement. For the same length of piping used in the SHX, it is possible to engineer an arrangement with longer contact times and a better quality of interaction between stormwater and SHX. Quantitatively, this would show up in the system of equations as a lower SHX thermal resistance. As an example, it is feasible that the SHX could be composed of long lengths of plastic piping laid in the effluent pipe leaving the vault or buried in the aggregate of an existing cooling trench in a similar lengthwise fashion. Presumably, this would encourage better heat transfer because contact time would be longer and the quality of interaction between SHX and stormwater would increase.

It is also possible to increase heat transfer by upgrading the SHX material. This pilot used HDPE pipe for the SHX. This pipe was inexpensive, robust, and straightforward to model. However, the SHX was large $(0.61 \mathrm{~m}$ high $\times 1.8 \mathrm{~m}$ diameter) because of the poor thermal conductivity of plastic. A metal heat exchanger would be much more space efficient. A stainless steel plate heat exchanger (for example, the Slim Jim or Geo Lake Plate heat exchangers from AWEB Geothermal) with comparable heat transfer would be $0.61 \mathrm{~m}$ wide $\times 1.8 \mathrm{~m}$ long but $<5 \mathrm{~cm}$ high, a fraction of the space currently being occupied by the plastic SHX. It follows that a large vault is not necessary. Advanced GHX design such as double U-bends (Kerme and Fung 2020), irregularly shaped pipes (Koenig 2015), and similar, could further enhance cooling.

\subsection{Future work}

- This article provided an example geothermal system sizing using monitoring data for the pilot pond from 2019. If detailed data for any given pond was available then the same process could be replicated, perhaps with corrections to the thermal load to consider weather in a typical or worst case year. However, we did not discuss a generalized sizing procedure that could be applied to new ponds or when detailed monitoring data was not available. We also did not discuss the integration of other thermal mitigation measures. The formulation of a generalized sizing procedure and sizing software tools should be the subject of future work.

- Pilots of larger scale systems should be the subject of future work, as should be the exploration of different SHX and GHX designs and approaches, and also the incorporation of other complementary thermal mitigation measures. Retrofits of underperforming cooling trenches is an especially relevant topic.

- This pilot used water as the hydronic fluid in the closed circuit. Measurements should be repeated 
using nontoxic antifreeze solutions like propylene glycol or ethanol.

\section{Conclusion}

SWM ponds are a common feature in new and existing developments. This article presented geothermal cooling as a new thermal mitigation option with several key benefits. Based on a small scale pilot conducted at a SWM pond located in Brampton, Ontario it was demonstrated that geothermal cooling is effective, space efficient, cost effective, highly engineerable, scalable, and retrofittable, and also that it does not visually impact the landscape of the pond. A model of the system was verified and used to design a procedure for a full scale system capable of keeping outflow temperatures within recommended limits $96 \%$ of the time during the summer. Future work should evaluate the performance of a larger system, consider opportunities for improvement and combination with other thermal mitigation measures, and further refine recommendations for system sizing and design. Overall, this article has demonstrated that geothermal cooling is a very promising new thermal mitigation option.

\section{Acknowledgments}

The main components of the system were constructed and integrated by Ricardo Brown, monitoring technician for STEP. Additional technical support was provided by Svend de Bruyn, David Nixon, Dean Luciani and Mark Hummel. Additional administrative support was provided by Christy Graham, Gil Amdurski and Leigh St. Hilaire. These contributors are all from the Sustainable Technologies Evaluation Program team. Supporting data for the analysis was provided by Geosource Energy Inc. Funding support from the City of Brampton is gratefully acknowledged. The authors also gratefully acknowledge base funding support for STEP projects from The Region of Peel, York Region, and The City of Toronto.

\section{References}

Chu, C., N.E. Jones, A.R. Piggott, and J.M. Buttle. 2009. “Evaluation of a Simple Method to Classify the Thermal Characteristics of Streams using a Nomogram of Daily Maximum Air and Water Temperatures." North American Journal of Fisheries Management 29 (6): 1605-1619. https://doi.org/10.1577/M08-251.1

Galli, J. 1990. Thermal Impacts Associated with Urbanization and Stormwater Management Best Management Practices. Report prepared by the Metropolitan Washington Council of Governments, Washington D.C. https://www.mwcog.org/documents/1990/12/12/thermal-impacts-associated-with-urbanization-and-stormwater-management-best-management-practices/

Hansen, G. 2011. Experimental testing and analysis of surface water heat exchangers. Stillwater, OK: Oklahoma State University, Master's thesis.
Hester, E.T., and K.S. Bauman. 2013. "Stream and Retention Pond Thermal Response to Heated Summer Runoff from Urban Impervious Surfaces." Journal of the American Water Resources Association 49 (2): 328-342. https://doi.org/10.1111/jawr.12019

Janssen, E., D. Zhang, and T. Van Seters. 2015. Performance Assessment of Urban Geoexchange Projects in the Greater Toronto Area. Toronto: Toronto and Region Conservation Authority, Sustainable Technologies Evaluation Program. https://www.sustainabletechnologies.ca/app/uploads/2015/03/GeoExchangeMonitoring_Final_Feb2015. pdf.

Karr, J.R. 1991. “Biological Integrity: A Long-Neglected Aspect of Water Resource Management." Ecological Applications 1 (1): 66-84. https://doi.org/10.2307/1941848

Kavanaugh, S., and K. Rafferty. 2014. Geothermal Heating and Cooling: Design of Ground-source Heat Pump Systems. Atlanta, GA: ASHRAE. ISBN 978-1-936504-85-5.

Kerme, E.D., and A. Fung. 2020. "Transient Heat Transfer Simulation, Analysis and Thermal Performance Study of Double U-tube Borehole Heat Exchanger Based on Numerical Heat Transfer Model." Applied Thermal Engineering 173. https://doi.org/10.1016/j.applthermaleng.2020.115189

Koenig, A.A. 2015. "Thermal Resistance of Borehole Heat Exchangers Composed of Multiple Loops and Custom Shapes." Geothermal Energy 3 (10). https://doi.org/10.1186/s40517-015-0029-1

Marsalek, P.M., W.E. Watt, J. Marsalek, and B.C. Anderson. 2003. "Winter Operation of an On-stream Stormwater Management Pond." Water Science and Technology 48 (9): 133-143. https://doi.org/10.2166/wst.2003.0510

Mayer, T., Q. Rochfort, U. Borgmann, and M. Brown. 1999. “Impact of Road Salts on Small Urban Ponds: Rouge River Pond Case Study." Burlington, Ontario: National Water Research Institute. NWRI Contribution 99-072.

McEnroe, N. A., J. M. Buttle, J. Marsalek, F. R. Pick, M. A. Xenopoulos, and P.C. Frost. 2013. "Thermal and Chemical Stratification of Urban Ponds: Are They 'Completely Mixed Reactors'?" Urban Ecosystems 16 (2): 327-339. https://doi.org/10.1007/s11252-012-0258-z

Nelson, K. C., and M. A. Palmer. 2007. "Stream Temperature Surges Under Urbanization and Climate Change: Data, Models, and Responses." Journal of the American Water Resources Association 43 (2): 440-452. https://doi.org/10.1111/j.1752-1688.2007.00034.x

Ontario Ministry of Environment (OMOE). 2003. Stormwater Management Planning and Design Manual. Toronto: Queen's Printer for Ontario. ISBN 0-7794-2969-9.

Roa-Espinosa, A., T.B. Wilson, J.M. Norman, and K. Johnson. 2003. "Predicting the Impacts of Urban Development on Stream Temperature Using a Thermal Urban Runoff Model (TURM)." 
In Proceedings of the National Conference on Urban Stormwater-Enhancing Programs at the Local Level, 369-89. Washington, DC: U.S. Environmental Protection Agency.

Sabouri, F., B. Gharabaghi, N. Perera, and E. McBean. 2013. “Evaluation of the Thermal Impact of Stormwater Management Ponds." Journal of Water Management Modeling 21:

R246-12.

https://doi.org/10.14796/JWMM.R246-12

Sabouri, F., B. Gharabaghi, E. McBean, and C. Tu. 2016. “Thermal Investigation of Stormwater Management Ponds." Journal of Water Management Modeling 24: C397. https://doi.org/10.14796/JWMM.C397

Song, K., M.A. Xenopoulos, J.M. Buttle, J. Marsalek, N.D. Wagner, F.R. Pick, and P.C. Frost. 2013. "Thermal Stratification Patterns in Urban Ponds and Their Relationships with Vertical Nutrient Gradients." Journal of Environmental Management 127: 317-23.

https://doi.org/10.1016/j.jenvman.2013.05.052
Van Buren, M.A., W.E. Watt, J. Marsalek, and B.C. Anderson. 2000a. "Thermal Enhancement of Stormwater Runoff by Paved Surfaces." Water Research 34 (4): 1359-71. https://doi.org/10.1016/S0043-1354(99)00244-4

Van Buren, M.A., W.E. Watt, J. Marsalek, and B.C. Anderson. 2000b. "Thermal Balance of On-stream Stormwater Management Pond." Journal of Environmental Engineering 126 (6): 509-17. https://doi.org/10.1061/(ASCE)0733-9372(2000)126:6(509)

Van Seters, T., C. Graham, J. Dougherty, C. Jacob-Okor, and Y. David. 2019. Data Synthesis and Design Considerations for Stormwater Thermal Mitigation Measures. Toronto: Toronto and Region Conservation Authority, Sustainable Technologies Evaluation Program.

https://sustainabletechnologies.ca/app/uploads/2019/04/ Thermal-Synthesis-Final.pdf 